\title{
Relationship between cervical and global sagittal balance in patients with dropped head syndrome
}

\author{
Kazuma Murata ${ }^{1} \cdot$ Kenji Endo $^{1} \cdot$ Takato Aihara $^{1} \cdot$ Hidekazu Suzuki $^{1} \cdot$ Yuji Matsuoka ${ }^{1} \cdot$ Hirosuke Nishimura $^{1}$. \\ Taichiro Takamatsu ${ }^{1} \cdot$ Takuya Kusakabe $^{1} \cdot$ Asato Maekawa $^{1} \cdot$ Kengo Yamamoto $^{1}$
}

Received: 21 October 2018 / Revised: 14 October 2019 / Accepted: 9 November 2019 / Published online: 14 January 2020

(c) The Author(s) 2020

\begin{abstract}
Background DHS is characterized by chin-on-chest deformity and devastatingly impedes activities of daily living in affected individuals. There is a paucity of literature about the pathophysiology of DHS including knowledge about spinal sagittal alignment. We conducted this study to clarify the relationship between cervical sagittal alignment and global sagittal balance in DHS.

Methods This is a retrospective radiographic study of a case series of DHS. Forty-one patients with diagnosed DHS were enrolled. Measurements were made using lateral standing radiograph.

Results C2-C7 sagittal vertical axis (SVA) was estimated as $52.0 \pm 2.4 \mathrm{~mm}$. Among sagittal parameters, C7-S1 SVA positively correlated with $\mathrm{C} 2-\mathrm{C} 7$ angle $(\mathrm{C} 2-\mathrm{C} 7 \mathrm{~A})(r=0.33)$. For the correlations between $\mathrm{C} 7$ and S1 SVA and C2-C7 A, both logistic and linear regression models were used to determine the threshold for $\mathrm{C} 2-\mathrm{C} 7 \mathrm{~A}$ value responsible for global sagittal balance. $\mathrm{C} 2-\mathrm{C} 7 \mathrm{~A}$ of -15.0 and 6.0 were predicted by logistic and linear regression models and were considered responsible for the occurrence of global positive imbalance. Therefore, we divided into two groups, namely, cervical kyphosis group (C type) and diffuse kyphosis group (D type) by median value of $\mathrm{C} 2-\mathrm{C} 7 \mathrm{~A}$. Enlarged thoracic kyphosis and global positive imbalance were observed in $\mathrm{D}$ type compared to $\mathrm{C}$ type.
\end{abstract}

Conclusion C2-C7 A exhibited correlations with cervical balance and also with global balance. There should be various type of thoraco-lumbar alignment in DHS.

\section{Graphic abstract}

These slides can be retrieved under Electronic Supplementary Material.
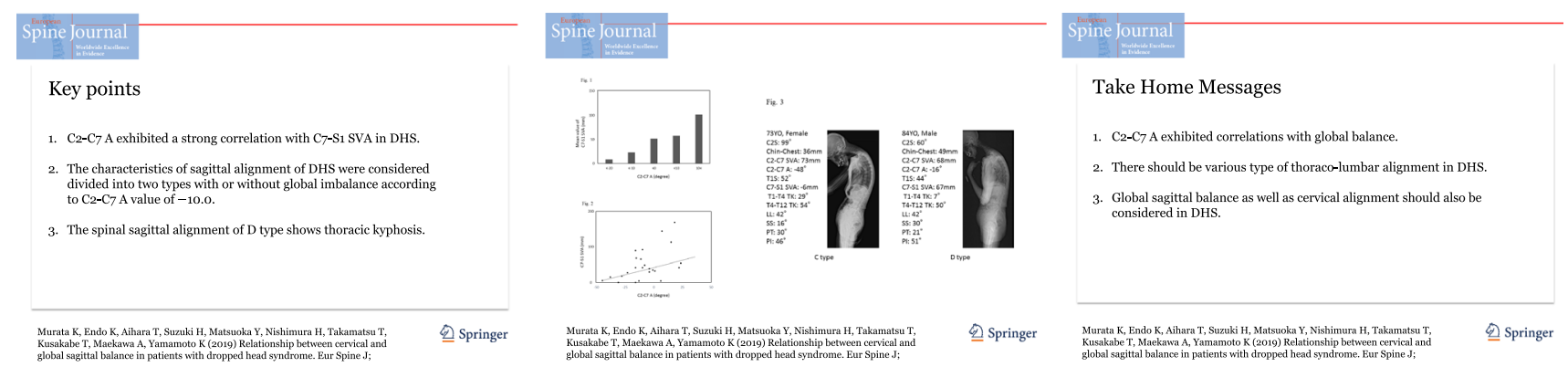

Keywords Dropped head syndrome $\cdot$ Sagittal balance $\cdot$ Cervical deformity $\cdot$ Sagittal alignment

Electronic supplementary material The online version of this article (https://doi.org/10.1007/s00586-019-06229-1) contains supplementary material, which is available to authorized users.

Kazuma Murata

kaz.mur26@gmail.com

Extended author information available on the last page of the article

\section{Introduction}

Dropped head syndrome (DHS) is characterized by chin-onchest deformity which is caused by severe extensor muscle weakness and is passively correctable with neck extension 
with normal passive neck range of motion [1]. This functional deformity arising from disability to balance the position of the head in standing or sitting posture impedes the quality of life of affected individuals significantly by inflicting various degrees of neck pain, difficulty in horizontal gaze, possible neurological symptoms, dysphagia or ambulation distress resulting in reduction in activities of daily living, and social interactions [2,3]. There is a dispute about the sagittal alignment of DHS, which is essential for understanding the pathophysiology and planning treatment including operative corrective surgery. A previous study reported that cervical positive imbalance results in anterior translation of the center of gravity of the head and loads the weight of the head increasingly on neck extensors [2]. Therefore, sagittal malalignment of spinal elements may be related for the development of DHS. The primary aim of the present study was to clarify the characteristics in sagittal alignment of DHS through radiographic measurements.

\section{Materials and methods}

After obtaining institutional review board approval, a retrospective analysis of radiographic profiles was performed for the patients who presented to our department with chinon-chest symptoms which were correctable in the supine position. All patients were referred to the Department of Neurology in our hospital to receive a neurological workup. Forty-one patients who were not found to have an underlying neurological condition and whose condition was diagnosed as isolated neck extensor myopathy (INEM) were included in this study: DHS may be confounded by a broad range of differential diagnosis such as Parkinson's disease [4], and INEM is considered to cause the chin-on-chest symptom in the absence of specific abnormality $[5,6]$. All patients provided informed consent by opt-out manner. Lateral standing radiographs were obtained by using vertical film with a constant distance between the subject and the radiographic source with a radio-opaque calibration tool, following a standardized protocol with the patients standing in a neutral fists-on-clavicle position and instructed to look straight ahead with knees locked [7-12]. The following spinal parameters were assessed: (1) C2 slope (C2S) which was measured as the angulation of the intersection between lines parallel to the $\mathrm{C} 2$ inferior end plate and the horizontal line, (2) C2-C7 lordosis angle (C2-C7 A) which was measured as the angulation of the intersection between lines parallel to the inferior end plates of $\mathrm{C} 2$ and $\mathrm{C} 7$, (3) C2-C7 sagittal vertical axis (C2-C7 SVA) which was measured as the distance between the $\mathrm{C} 2$ plumb line and $\mathrm{C} 7$ supero-posterior corner, (4) T1 slope (T1S) which was measured as the angulation of the intersection between lines parallel to the $\mathrm{T} 1$ superior end plate and the horizontal line, (5) C7-S1 sagittal vertical axis
(C7-S1 SVA) which was measured as the distance between the $\mathrm{C} 7$ plumb line and $\mathrm{S} 1$ supero-posterior corner, (6) T1-T4 thoracic kyphosis angle (T1-T4 TK) which was measured as the angulation of the intersection between lines parallel to the $\mathrm{T} 1$ superior end plate and the T4 inferior end plate, (7) T4-T12 thoracic kyphosis angle (T4-T12 TK) which was measured as the angulation of the intersection between lines parallel to the $\mathrm{T} 4$ superior end plate and the $\mathrm{T} 12$ inferior end plate, (8) lumbar lordosis (LL) which was measured as the angulation of the intersection between lines parallel to the superior end plate of T12 and the sacrum, (9) sacral slope (SS) which was measured as the angulation of the intersection between lines parallel to the superior end plates of the sacrum and the horizontal line, (10) pelvic tilt (PT) which was measured as the angulation of the intersection between lines parallel to a line connecting the midpoint of the superior end plate of the sacrum to the center of the hip axis and the vertical line, and (11) pelvic incidence (PI) which was measured as the angulation of the intersection between lines parallel to a line connecting the midpoint of the superior end plate of the sacrum to the center of the hip axis and a perpendicular line to the superior end plate of the sacrum $[13,14]$. The accuracy of the methods, including intra-rater and interrater agreements, was analyzed in detail in a previous paper [15]. We also measure chin-chest distance determined as the distance between the tip of jaw and the apex of the sternum.

Statistical analysis was performed using commercially available software (JMP version 11.0; SAS Institute, Inc., Cary, NC, USA). After determining that the data followed a parametric distribution using the Shapiro-Wilk normality test (where $P>0.05$ suggests that the data are from a normal distribution), student $t$ tests were calculated to compare the two groups (Diffuse kyphosis type: D type vs. Cervical kyphosis type: C type), and Pearson product-moment correlation coefficients were calculated for all combinations of radiographic measurements. The level of significance was set at $P<0.05$. For significant correlations observed among radiographic parameters, further analyses, using both linear regression and logistic regression analyses with binary variables, were performed to determine a possible threshold of radiographic measurement was most significant.

\section{Results}

\section{Patient characteristics}

Twenty-seven female and 14 male patients with DHS with an average age of $73.0 \pm 1.9$ years (range, $42-87$ ) who agreed to participate were enrolled in this study. The patients who had evidence of diffuse idiopathic skeletal hyperostosis inside or outside the cervical region were excluded from the analysis. 


\section{Radiographic measurements}

Radiographic measurements are summarized in Table 1. C2-C7 SVA, which was representative of head balance, exhibited positive imbalance $(52.0 \pm 2.4 \mathrm{~mm})$, determined by C2-C7 SVA $>40 \mathrm{~mm} \mathrm{[16].} \mathrm{C2S} \mathrm{and} \mathrm{T1S} \mathrm{were} \mathrm{enlarged}$ (C2S: $\left.49.8^{\circ} \pm 1.8^{\circ}, \mathrm{T} 1 \mathrm{~S}: 33.1^{\circ} \pm 2.2^{\circ}\right)$. Decreased C2-C7 A represents the kyphotic contour of DHS $\left(-8.7^{\circ} \pm 3.2^{\circ}\right)$.

\section{Statistical analysis}

Correlations among radiographic measurements are summarized in Table 2. C2-C7 A exhibited significant correlations

Table 1 Radiographic measures of standing total spine

\begin{tabular}{lc}
\hline & DHS \\
\hline C2S & $49.8^{\circ} \pm 1.8^{\circ}$ \\
Chin-chest distance & $59.1 \pm 1.4 \mathrm{~mm}$ \\
C2-C7 SVA & $52.0 \pm 2.4 \mathrm{~mm}$ \\
C2-C7 A & $-8.7^{\circ} \pm 3.2^{\circ}$ \\
T1S & $33.1^{\circ} \pm 2.2^{\circ}$ \\
C7-S1 SVA & $38.6 \pm 9.0 \mathrm{~mm}$ \\
T1-T4 TK & $14.4^{\circ} \pm 2.1^{\circ}$ \\
T4-T12 TK & $32.9^{\circ} \pm 2.9^{\circ}$ \\
LL & $36.4^{\circ} \pm 2.9^{\circ}$ \\
SS & $26.0^{\circ} \pm 1.8^{\circ}$ \\
PT & $24.4^{\circ} \pm 2.0^{\circ}$ \\
PI & $48.3^{\circ} \pm 2.3^{\circ}$ \\
\hline
\end{tabular}

DHS, dropped head syndrome; C2S, C2 slope; C2-C7 SVA, C2-C7 sagittal vertical axis; C2-C7 A, C2-C7 lordosis angle; T1S, T1 slope; C7-S1 SVA, C7-S1 sagittal vertical axis; TK, thoracic kyphosis angle; LL, lumbar lordosis angle; SS, sacral slope; PT, pelvic tilt; PI, pelvic incidence with thoraco-lumbar parameters (T1S: $r=0.39, P=0.01$; C7-S1 SVA: $r=0.33, P=0.04$; T4-T12 TK: $r=0.39$, $P=0.02$; SS: $r=-0.39, P=0.02$, respectively). T1S exhibited significant positive correlations with cervical parameters (C2-C7 A: $r=0.39, P=0.01$; $2-C 7$ SVA: $r=0.48$, $P=0.002$, respectively) and thoraco-lumbar parameters (C7-S1 SVA: $r=0.67, P<0.001$; T1-T4 TK: $r=0.33$, $P=0.04$; T4-T12 TK: $r=0.45, P=0.004$; PT: $r=0.36$, $P=0.03)$. C2-C7 SVA did not exhibited significant correlation with thoraco-lumbar paramenter except for T1S.

For the strong correlation between $\mathrm{C} 2-\mathrm{C} 7 \mathrm{~A}$ and $\mathrm{C} 7-\mathrm{S} 1$ SVA, both logistic and linear regression analyses were used to determine a possible radiographic threshold at which global positive imbalance occurs, which was defined by C7-S1 SVA $>50 \mathrm{~mm}$ [17]. The logistic regression models predicted a value of -15.0 for $\mathrm{C} 2-\mathrm{C} 7 \mathrm{~A}\left(\chi^{2}=7.1, P=0.008\right)$ (Fig. 1) at which the $P$ value for the correlation tests was lowest. Values of AUC calculated from ROC curves were estimated at 0.77 for the analysis, and seemed to accurately represent the results. The linear regression models predicted values of 6.0 for $\mathrm{C} 2-\mathrm{C} 7 \mathrm{~A}\left(r^{2}=0.11, P=0.05\right)$ (Fig. 2) responsible for a C7-S1 SVA value of $50 \mathrm{~mm}$; C7-S1 SVA value of $50 \mathrm{~mm}$ represents global positive imbalance. Relative risk was also estimated at 2.9 -fold $(95 \%$ confidence interval $[\mathrm{CI}]=1.0-8.8)$ in the case of $\mathrm{C} 2-\mathrm{C} 7 \mathrm{~A}>-10$ which was a median value of $\mathrm{C} 2-\mathrm{C} 7 \mathrm{~A}$, and the odds ratio was estimated at 4.5 -fold $(95 \%$ confidence interval $[\mathrm{CI}]=1.0-20.5$ ) for the occurrence of global positive imbalance from the logistic analysis, where $P$ value was estimated at 0.04 .

\section{Comparison between two types of DHS}

For analysis obtained from the regression models, we classified DHS into two groups based on $\mathrm{C} 2-\mathrm{C} 7 \mathrm{~A}$, and set the

Table 2 Correlations among radiographic measures

\begin{tabular}{|c|c|c|c|c|c|c|c|c|c|c|c|}
\hline & $\mathrm{C} 2 \mathrm{~S}$ & $\mathrm{C} 2-\mathrm{C} 7 \mathrm{~A}$ & C2-C7 SVA & T1S & C7-S1 SVA & $\mathrm{T} 1-\mathrm{T} 4$ & $\mathrm{~T} 4-\mathrm{T} 12$ & LL & SS & PT & PI \\
\hline $\mathrm{C} 2 \mathrm{~S}$ & 1 & & & & & & & & & & \\
\hline $\mathrm{C} 2-\mathrm{C} 7 \mathrm{~A}$ & -0.13 & 1 & & & & & & & & & \\
\hline C2-C7 SVA & 0.11 & -0.27 & 1 & & & & & & & & \\
\hline T1S & -0.11 & $0.39 *$ & $0.48 *$ & 1 & & & & & & & \\
\hline C7-S1 SVA & -0.05 & $0.33 *$ & 0.24 & $0.67 *$ & 1 & & & & & & \\
\hline $\mathrm{T} 1-\mathrm{T} 4$ & 0.12 & 0.05 & 0.20 & $0.33 *$ & 0.28 & 1 & & & & & \\
\hline $\mathrm{T} 4-\mathrm{T} 12$ & -0.12 & $0.39 *$ & 0.12 & 0.45 & $0.62 *$ & $0.41 *$ & 1 & & & & \\
\hline LL & -0.16 & 0.06 & -0.22 & -0.04 & -0.23 & -0.18 & -0.09 & 1 & & & \\
\hline SS & 0.02 & $-0.39 *$ & 0.05 & -0.08 & -0.10 & -0.09 & -0.06 & 0.68 & 1 & & \\
\hline $\mathrm{PT}$ & -0.08 & 0.27 & 0.05 & $0.36^{*}$ & $0.44 *$ & 0.05 & $0.39 *$ & -0.16 & $-0.33^{*}$ & 1 & \\
\hline PI & -0.06 & -0.15 & 0.08 & 0.22 & 0.21 & -0.02 & 0.26 & $0.48 *$ & $0.64 *$ & $0.51^{*}$ & 1 \\
\hline
\end{tabular}

C2S, C2 slope; C2-C7 A, C2-C7 lordosis angle; C2-C7 SVA, C2-C7 sagittal vertical axis; T1S, T1 slope; C7-S1 SVA, C7-S1 sagittal vertical axis; LL, lumbar lordosis angle; SS, sacral slope; PT, pelvic tilt; PI, pelvic incidence

*indicates $P<0.05$ 


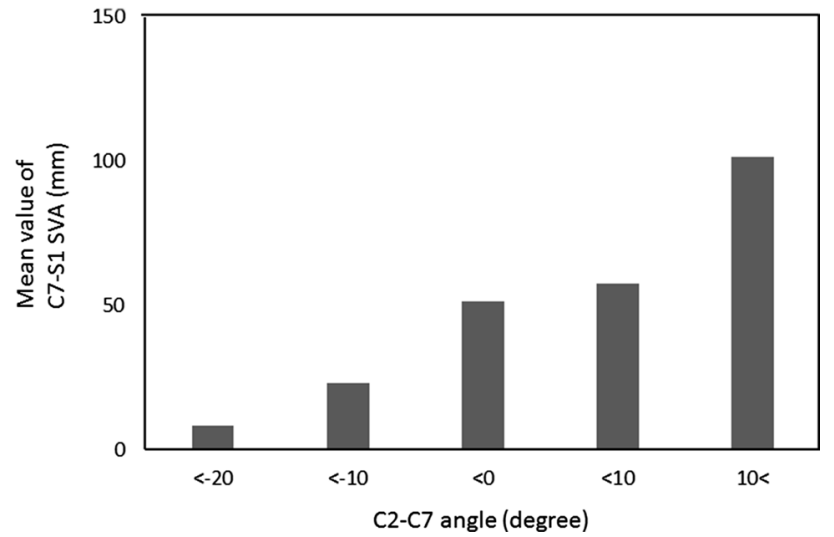

Fig. 1 Bar graph of mean data

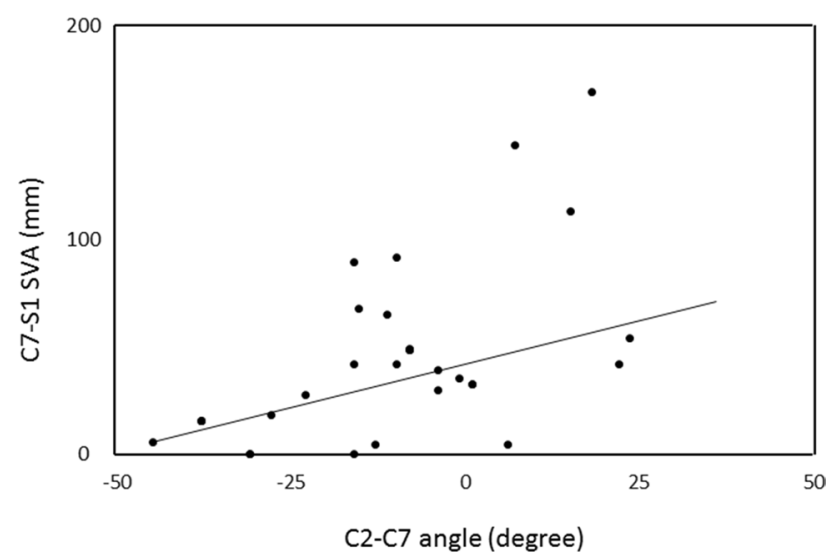

Fig. 2 Visual representation of the regression models superimposed on raw data. Positive correlation was observed between dropped head index (DH index) and C7-S1 sagittal vertical axis (C7-S1 SVA)

thresholds for $\mathrm{C} 2-\mathrm{C} 7 \mathrm{~A}$ of $-10^{\circ}$ : the patients with $\mathrm{C} 2-\mathrm{C} 7$ A $>-10^{\circ}$ were classified into diffuse kyphosis type (D type) and others were classified into cervical kyphosis type (C type). Comparisons of radiographic measures between two groups are summarized in Table 3. These comparisons between two groups revealed the differences in thoracic contour. Kyphotic contour represented by enlarged T4-T12 TK was observed in D group (T4-T12 TK: $42.8^{\circ} \pm 3.1^{\circ}$ vs. $28.5^{\circ} \pm 3.3^{\circ}$.

\section{Discussion}

We observed enlarged offset of gravity of the head represented by $\mathrm{C} 2-\mathrm{C} 7 \mathrm{SVA}$, and the correlation of $\mathrm{C} 2-\mathrm{C} 7 \mathrm{~A}$ with C7-S1 SVA. For this correlation, we classified DHS into two groups based on $\mathrm{C} 2-\mathrm{C} 7 \mathrm{~A}$. The comparison analysis of two groups revealed there were two different type of thoracolumbar alignment in DHS.
Table 3 Comparison of radiographic measures between two groups

\begin{tabular}{lccc}
\hline & D type & C type & $P$ value \\
\hline C2S & $49.4^{\circ} \pm 2.5^{\circ}$ & $50.3^{\circ} \pm 2.7^{\circ}$ & 0.81 \\
C2-C7 A & $3.2^{\circ} \pm 3.4^{\circ}$ & $-22.6^{\circ} \pm 3.7^{\circ}$ & $<0.001$ \\
C2-C7 SVA & $49.8 \pm 3.2 \mathrm{~mm}$ & $54.6 \pm 3.5 \mathrm{~mm}$ & 0.31 \\
T1S & $37.9^{\circ} \pm 2.9^{\circ}$ & $27.6^{\circ} \pm 3.1^{\circ}$ & 0.02 \\
C7-S1 SVA & $53.6 \pm 11.3 \mathrm{~mm}$ & $16.6 \pm 11.3 \mathrm{~mm}$ & 0.03 \\
T1-T4 TK & $13.0^{\circ} \pm 2.6^{\circ}$ & $13.0^{\circ} \pm 2.7^{\circ}$ & 0.23 \\
T4-T12 TK & $42.8^{\circ} \pm 3.1^{\circ}$ & $28.5^{\circ} \pm 3.3^{\circ}$ & 0.003 \\
LL & $40.9^{\circ} \pm 3.3^{\circ}$ & $34.4^{\circ} \pm 3.6^{\circ}$ & 0.19 \\
SS & $25.3^{\circ} \pm 2.4^{\circ}$ & $27.4^{\circ} \pm 2.6^{\circ}$ & 0.57 \\
PT & $24.2^{\circ} \pm 2.2^{\circ}$ & $21.6^{\circ} \pm 2.4^{\circ}$ & 0.43 \\
PI & $49.1^{\circ} \pm 2.5^{\circ}$ & $48.8^{\circ} \pm 2.7^{\circ}$ & 0.93 \\
\hline
\end{tabular}

C2S, C2 slope, C2-C7 SVA, C2-C7 sagittal vertical axis, C2-C7 A, C2-C7 lordosis angle, T1S, T1 slope, C7-S1 SVA, C7-S1 sagittal vertical axis, TK, thoracic kyphosis angle, LL, lumbar lordosis angle, SS, sacral slope, PT, pelvic tilt, PI, pelvic incidence

It may be difficult to interpret these findings as actual causes of DHS because this was a cross-sectional study. However, some recent studies described the relationship between cervical sagittal alignment and other regions of the spinal column $[18,19]$. With regard to a reciprocal relationship between the cervical and other parts of the spinal column, global sagittal imbalance leads to adaptive changes in the pelvis through a compensatory mechanism [18]. Hence, we assumed that the loss of head balance without global imbalance is a result of degenerative changes accompanied with anterior disk collapse at the middle and lower cervical spine, and named C type (Fig. 3). In contrast, the loss of balance with global positive imbalance is originated from global positive imbalance, which is named D type (Fig. 3). Finally in both types, with a progressing anterior shift of the head without balance and loss of tissue elasticity of the extensor muscle, the overstretched extensor muscles cannot maintain the head position in the standing or sitting position. Previously, sagittal spinal alignment in the DHS patient was simply described as a chin-on-chest deformity associated with cervicothoracic kyphosis. In fact, there should be various types of DHS alignment, as revealed in the current study.

Increased T4-T12 TK was observed in the D type compared to the $\mathrm{C}$ type. These results suggest the difference in affected muscles between the two types. The semispinalis capitis (originating from the T1-T6 transverse processes and $\mathrm{C} 4-\mathrm{C} 6$ articular processes, inserting at the occipital bone, innervated by posterior branches of spinal nerves), semispinalis cervicis (originating from the C7-T6 transverse processes, inserting at the $\mathrm{C} 2-\mathrm{C} 5$ spinal processes, innervated by posterior branches of spinal nerves), and semispinalis thoracis (originating from the T6-T12 transverse processes, inserting at the C6-T4 spinal processes, innervated by posterior branches of spinal nerves) are 
Fig. 3 Representative standing radiographs of C type DHS. In $\mathrm{C}$ type, cervical imbalance is accompanied with severe cervical kyphosis and compensated by the spinopelvic complex, which shows balanced global balance. Patient: 73YO, Female. Sagittal parameters: C2S: $99^{\circ}$, Chin-chest distance: $36 \mathrm{~mm}$, C2-C7 SVA: $73 \mathrm{~mm}, \mathrm{C} 2-\mathrm{C} 7$ angle: $-48^{\circ}$, T1S: $52^{\circ}, \mathrm{C} 7-\mathrm{S} 1$ SVA: $-6 \mathrm{~mm}, \mathrm{~T} 1-\mathrm{T} 4 \mathrm{TK}: 29^{\circ}$, T4-T12 TK: $54^{\circ}$, LL: $42^{\circ}$, SS: $16^{\circ}, \mathrm{PT}: 30^{\circ}, \mathrm{PI}: 46^{\circ}$

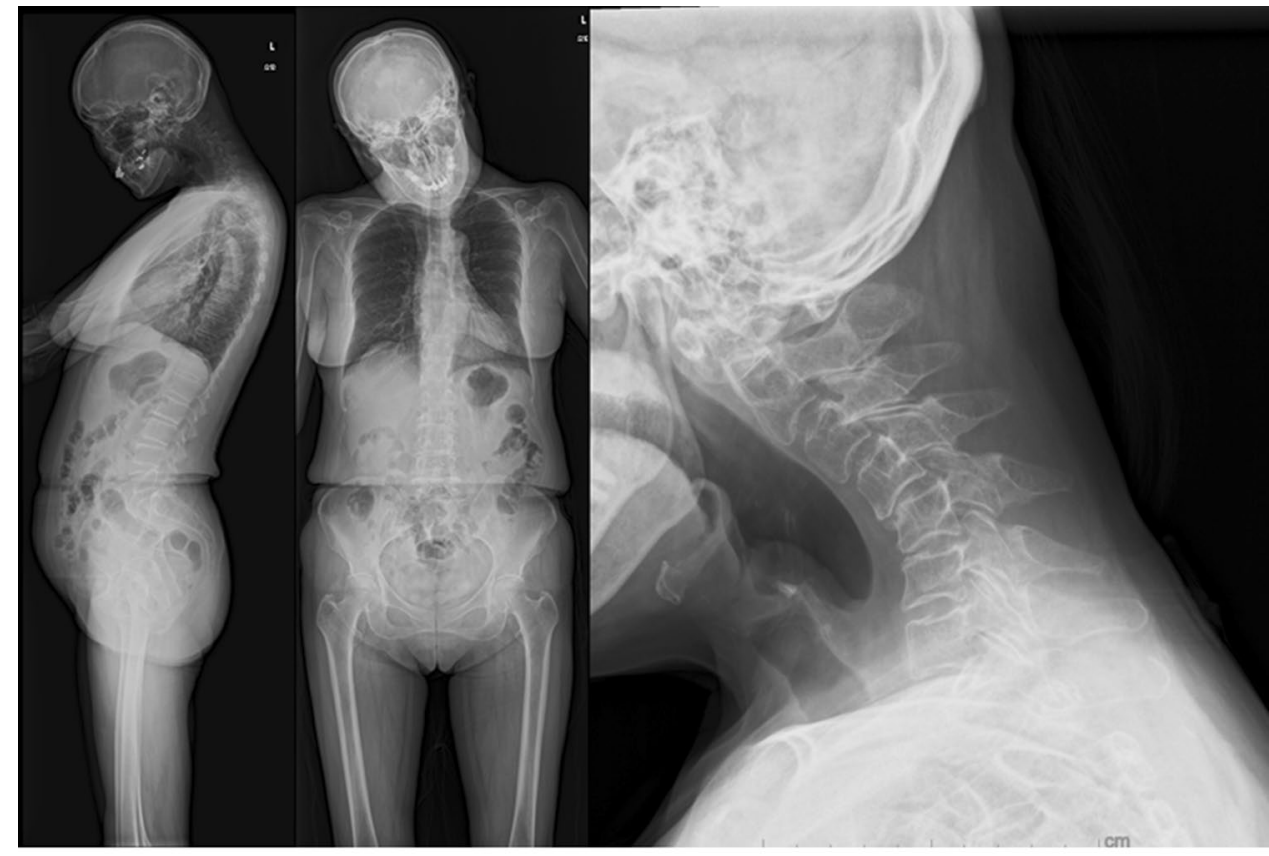

C type considered as the main extensors in the deep layer of the cervicothoracic region [20]. These semispinalis muscles may be responsible for the pathophysiology of INEM from the anatomical point of view. One report suggested the cause of DHS as the semispinalis capitis, in a middle-aged female patient with sepsis [21], which may tend to occur in the D type in light of the distribution of the muscle. On the other hand, the suboccipital group, which comprises the rectus capitis posterior major, rectus capitis posterior minor, obliquus capitis superior, and obliquus capitis inferior (originating from $\mathrm{C} 1-\mathrm{C} 2$, inserting at the occipital bone, innervated by posterior primary divisions of spinal nerves), and spinalis cervicis (originating from the nuchal ligament, and the C7-T1 spinous processes, inserting at the $\mathrm{C} 2$ spinous process, innervated by anterior branches of spinal nerves) are a complex of the extensors in the deep
Fig. 4 Representative standing radiograph of $\mathrm{D}$ type shows the loss of head balance with relatively milder cervical kyphosis and shows diffuse positive imbalance. Patient: 78YO, Female. Sagittal parameters: C2S: $58^{\circ}$, Chin-Chest distance: $51 \mathrm{~mm}, \mathrm{C} 2-\mathrm{C} 7 \mathrm{SVA}$ : $60 \mathrm{~mm}$, C2-C7 angle: $-5^{\circ}$, T1S: $56^{\circ}$, C7-S1 SVA: $86 \mathrm{~mm}, \mathrm{~T} 1-\mathrm{T} 4$ TK: $3^{\circ}$, T4-T12 TK: 52 ${ }^{\circ}$, LL: $25^{\circ}, \mathrm{SS}: 23^{\circ}, \mathrm{PT}: 29^{\circ}, \mathrm{PI}: 52^{\circ}$

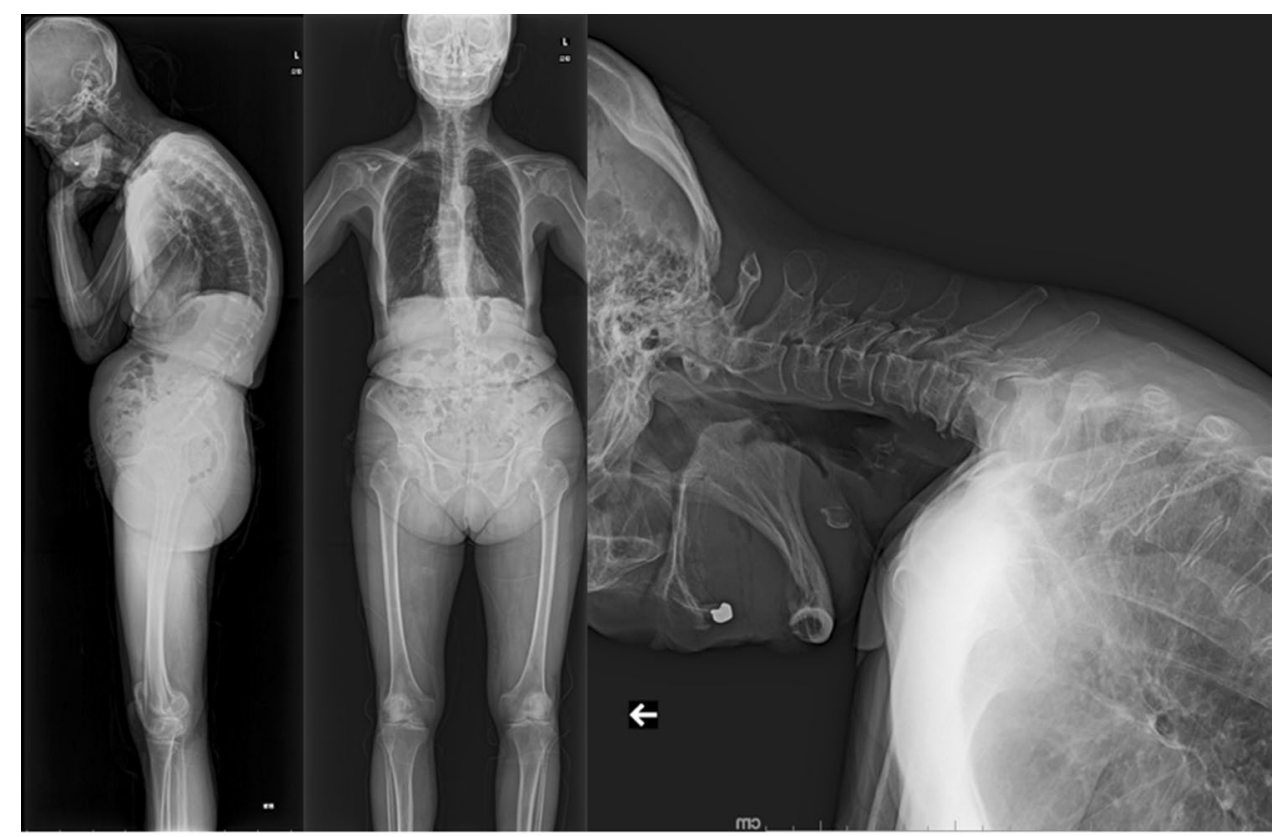

D type 
layer of the cervical region and is considered affected in the $\mathrm{C}$ type for the distribution localized in the cervical region [22]. These differences might be considered as a target region in corrective surgery, and different strategies in conservative treatments are also required for each type. The cervical spine of the $\mathrm{C}$ type can be supported by only a cervical brace, but that of the $\mathrm{D}$ type requires an additional thoracic band in order to support the thoracic spine (Fig. 4).

The current study may have some limitations. First, the number of cases of INEM DHS is small, reflecting the small number of DHS patients in general, and the population may have skewed characteristics arising from inclusion criteria of this uncommon condition. Despite these limitations, we consider this study to provide some contribution to understanding the pathophysiology of DHS in view of performing optimal treatment.

\section{Conclusion}

Increased offset of the gravity axis of the head, which was represented by C2-C7 SVA, was observed in DHS. Among cervical parameters, $\mathrm{C} 2-\mathrm{C} 7$ A exhibited strong correlation with global balance. For these correlations, we made regression analyses on these parameters and classified DHS into two types according to the $\mathrm{C} 2-\mathrm{C} 7 \mathrm{~A}$ value of -10.0 . The spinal sagittal alignment of $\mathrm{D}$ type shows thoracic kyphosis compared to $\mathrm{C}$ type.

Acknowledgements The authors are indebted to the medical editors from the Department of International Medical Communications of Tokyo Medical University for editing and reviewing the initial English manuscript.

Funding None.

\section{Compliance with ethical standards}

Conflict of interest The authors declare no conflict of interest in any form received from a commercial party related directly or indirectly to this study.

Ethical approval This study was approved by the Ethics Review Committee of Tokyo Medical University Hospital. Written informed consent was obtained from all patients before the recruitment of patients in this study.

Open Access This article is licensed under a Creative Commons Attribution 4.0 International License, which permits use, sharing, adaptation, distribution and reproduction in any medium or format, as long as you give appropriate credit to the original author(s) and the source, provide a link to the Creative Commons licence, and indicate if changes were made. The images or other third party material in this article are included in the article's Creative Commons licence, unless indicated otherwise in a credit line to the material. If material is not included in the article's Creative Commons licence and your intended use is not permitted by statutory regulation or exceeds the permitted use, you will need to obtain permission directly from the copyright holder. To view a copy of this licence, visit http://creativecommons.org/licenses/by/4.0/.

\section{References}

1. Sharan AD, Kaye D, Charles Malveaux WM et al (2012) Dropped head syndrome: etiology and management. J Am Acad Orthop Surg 20:766-774

2. Martin AR, Reddy R, Fehlings MG (2011) Dropped head syndrome: diagnosis and management. Evid Based Spine Care J 2:41-47

3. Caruso L, Barone G, Farneti A et al (2014) Pedicle subtraction osteotomy for the treatment of chin-on-chest deformity in a postradiotherapy dropped head syndrome: a case report and review of literature. Eur Spine J 23:634-643

4. Petheram TG, Hourigan PG, Emran IM et al (2008) Dropped head syndrome: a case series and literature review. Spine 33:47-51

5. Suarez GA, Kelly JJ (1992) The dropped head syndrome. Neurology 42:1625-1627

6. Katz JS, Wolfe GI, Burns DK et al (1996) Isolated neck extensor myopathy: a common cause of dropped head syndrome. Neurology 46:917-921

7. Glassman SD, Berven S, Bridwell K et al (2005) Correlation of radiographic parameters and clinical symptoms in adult scoliosis. Spine 30:682-688

8. Matsuoka Y, Suzuki H, Endo K et al (2018) Small sagittal vertical axis accompanied with lumbar hyperlordosis as a risk factor for developing postoperative cervical kyphosis after expansive opendoor laminoplasty. J Neurosurg Spine 29:176-181

9. Murata K, Endo K, Suzuki H et al (2018) Sagittal alignment in patients with dropped head syndrome. Spine 43:E1267-E1273

10. Suzuki H, Endo K, Mizuochi J et al (2016) Sagittal lumbo-pelvic alignment in the sitting position of elderly persons. J Orthop Sci 21:713-717

11. Schwab F, Lafage V, Boyce R et al (2006) Gravity line analysis in adult volunteers: age-related correlation with spinal parameters, pelvic parameters, and foot position. Spine 31:E959-E967

12. Gore DR, Sepic SB, Gardner GM et al (1987) Neck pain: a longterm follow-up of 205 patients. Spine 12:1-5

13. Lafage V, Schwab F, Patel A et al (2009) Pelvic tilt and truncal inclination: two key radiographic parameters in the setting of adults with spinal deformity. Spine 34:E599-E606

14. Smith JS, Lafage V, Ryan DJ et al (2013) Association of myelopathy scores with cervical sagittal balance and normalized spinal cord volume: analysis of 56 preoperative cases from the AOSpine North America Myelopathy study. Spine 38:S161-S170

15. Suzuki H, Endo K, Kobayashi H et al (2010) Total sagittal spinal alignment in patients with lumbar canal stenosis accompanied by intermittent claudication. Spine 35:E344-E346

16. Tang JA, Scheer JK, Smith JS et al (2012) The impact of standing regional cervical sagittal alignment on outcomes in posterior cervical fusion surgery. Neurosurgery 71:662-669

17. Schwab F, Patel A, Ungar B et al (2010) Adult spinal deformitypostoperative standing imbalance: how much can you tolerate? An overview of key parameters in assessing alignment and planning corrective surgery. Spine 35:2224-2231

18. Ames CP, Blondel B, Scheer JK et al (2013) Cervical radiographical alignment: comprehensive assessment techniques and potential importance in cervical myelopathy. Spine 38:S149-S160

19. Smith JS, Lafage V, Schwab FJ et al (2014) Prevalence and type of cervical deformity among 470 adults with thoracolumbar deformity. Spine 39:E1001-E1009 
20. Nolan JP, Sherk HH (1988) Biomechanical evaluation of the extensor musculature of the cervical spine. Spine 13:9-11

21. Wang SH, Juan CJ, Lin TY (2014) Dropped head syndrome in a patient with Aeromonas hydrophila-induced septic arthritis of the shoulder. Arch Iran Med 17:850-852

22. Martin A (1994) Spinalis capitis, or an accessory paraspinous muscle? J Anat 185:195-198
Publisher's Note Springer Nature remains neutral with regard to jurisdictional claims in published maps and institutional affiliations.

\section{Affiliations}

\section{Kazuma Murata ${ }^{1} \cdot$ Kenji Endo $^{1} \cdot$ Takato Aihara $^{1} \cdot$ Hidekazu Suzuki $^{1} \cdot$ Yuji Matsuoka ${ }^{1} \cdot$ Hirosuke Nishimura $^{1}$. Taichiro Takamatsu ${ }^{1} \cdot$ Takuya Kusakabe $^{1} \cdot$ Asato Maekawa $^{1} \cdot$ Kengo Yamamoto $^{1}$}

1 Department of Orthopedic Surgery, Tokyo Medical

University, 6-7-1 Nishishinjuku, Shinjuku-ku,

Tokyo 160-0023, Japan 